\title{
Impacts of dynamic degradation on the morphological and mechanical characterisation of porous magnesium scaffold
}

\author{
Amir Putra Md Saad ${ }^{1,2} \cdot$ Akbar Teguh Prakoso $^{3} \cdot$ M. A. Sulong ${ }^{1,2} \cdot$ Hasan Basri $^{3} \cdot$ Dian Agustin Wahjuningrum ${ }^{4}$. \\ Ardiyansyah Syahrom ${ }^{1,2}$ (i)
}

Received: 24 January 2018 / Accepted: 26 December 2018 / Published online: 3 January 2019

(c) Springer-Verlag GmbH Germany, part of Springer Nature 2019

\begin{abstract}
This study employs a computational approach to analyse the impact of morphological changes on the structural properties of biodegradable porous $\mathrm{Mg}$ subjected to a dynamic immersion test for its application as a bone scaffold. Porous $\mathrm{Mg}$ was immersed in a dynamic immersion test for 24,48 , and $72 \mathrm{~h}$. Twelve specimens were prepared and scanned using micro-CT and then reconstructed into a 3D model for finite element analysis. The structural properties from the numerical simulation were then compared to the experimental values. Correlations between morphological parameters, structural properties, and fracture type were then made. The relative losses were observed to be in agreement with relative mass loss done experimentally. The degradation rates determined using exact (degraded) surface area at particular immersion times were on average $20 \%$ higher than the degradation rates obtained using original surface area. The dynamic degradation has significantly impacted the morphological changes of porous $\mathrm{Mg}$ in volume fraction, surface area, and trabecular separation, which in turn affects its structural properties and increases the immersion time.
\end{abstract}

Keywords Dynamic immersion test · Finite element analyses $\cdot$ Dynamic degradation $\cdot$ Porous magnesium $\cdot$ Morphological parameters

\section{Introduction}

Bone scaffolds made of biodegradable metal for cancellous bone replacement has been shown to be promising scaffolds for triggering new bone matrices and are good for loadbearing purposes while the bone is healing. The degradation

Amir Putra Md Saad

amirputra@utm.my

$\bowtie$ Ardiyansyah Syahrom

ardiyans@gmail.com

1 Applied Mechanics and Design, School of Mechanical Engineering, Faculty of Engineering, Universiti Teknologi Malaysia (UTM), 81310 Johor Bahru, Malaysia

2 Medical Devices and Technology Centre (MEDITEC), Institute of Human Centred and Engineering (iHumEn), Universiti Teknologi Malaysia (UTM), 81310 Johor Bahru, Malaysia

3 Department of Mechanical Engineering, Faculty of Engineering, Universitas Sriwijaya, Palembang, Indonesia

4 Department of Conservative Dentistry, Faculty of Dental Medicine, Universitas Airlangga, Surabaya, Indonesia of biodegradable metal can be determined extensively by means of weight loss measurement and electrochemical analyses, both of which are in vitro test measurements. However, it is very difficult to measure the degradation of biodegradable metal inside animal bones using in vivo measurement. Therefore, for animal testing measurement, degradation is often determined using computed tomography (CT). From the CT data set, parameters such as the morphological and structural properties of the remaining degraded material can be analysed using an image analyser and finite element analysis (FEA), respectively. At the same time, new tissue that grows while the bone is healing can also be closely monitored. Cancellous bone acts as the host tissue once the scaffold is implanted. It possesses a complex micro-architecture, which plays a major role in determining cancellous bone properties and bone quality (Judex et al. 2003; Shi et al. 2009). In order to effectively integrate bone scaffold with the host tissue, the physical characteristics of the scaffold such as porosity and mechanical properties should be similar to those of cancellous bone (Bose et al. 2012). In addition, controlled degradation rate of the materials-as structural supports-at the earliest stage of bone 
healing is critically important (Zheng et al. 2014). Biodegradable metals such as magnesium and its alloys have fascinating features that make them suitable as bone scaffolds. $\mathrm{Mg}$ has the potential to degrade in vivo without causing toxicological problems (Zheng et al. 2014). Besides that, it induces stimulatory effects in bone growth due to the formation of bone apatites such as hydroxyapatite crystals (Bigi et al. 1993) and possesses mechanical properties similar to human cancellous bone (Md. Saad et al. 2016). Therefore, to track the physical changes in porous magnesium under a dynamic degradation environment, the degradation rate and morphology were analysed using CT measurement data sets and the structural properties were determined using FEA.

Cancellous bone is a key structural support in loadbearing applications. Besides supporting more than $75 \%$ of the total body weight (Liu et al. 2009), it also acts as a counter load through the cortical bone structure. The proficient micro-architecture of a cancellous bone structure significantly functions as an absorber upon mechanical loading. Mechanical loads from physiological activities induce tensile, compressive, and shear stresses on the cortical bone. These are adjusted by the bore of the cancellous bone (Liu et al. 2009). These stresses are important for triggering the bone remodelling process to provide bone strength. The mechanical properties of the material such as modulus of elasticity, compressive and tensile strength are also important. These properties are highly dependent on viscoelasticity (depending on the load applied) and anisotropy (depending on load orientation) (Helgason et al. 2008). The relationship between the morphological and structural properties of cancellous bone was measured via experimental works as well as computational methods (Syahrom et al. 2011). The structural properties have been widely assessed through compression tests in experimental works; however, acquiring the morphological information of materials by means of experimental works is difficult and almost impossible (Sulong et al. 2016). Computational methods are much more preferred, as they provide the morphological details of materials up to the micro-level, especially for irregular or complex porous structures.

A scaffold with a porous structure is known to promote tissues interlocking, cell migration, and nutrient transport as well as osteo-integration with replaced host tissues (Gong et al. 2015). Another advantage of using a porous structure is that the pore size and surface area of the scaffolds can be controlled and regulated precisely to the desired forms, shapes, and structural property (Lewis 2013; Syahrom et al. 2013; Bobe et al. 2013; Cheng et al. 2016). Similar to cancellous bone, different skeletal sites have different porosities depending on their functional properties. The Young's modulus of cancellous bone usually decreases as porosity increases (Shimko et al. 2005). The percentage porosity of human cortical bone is between 2 and 7\% (Renders et al.
2007), while cancellous bone is between 30 and $95 \%$ porous (Snyder et al. 1993; Morgan and Keaveny 2001; Renders et al. 2007; Tamburaci and Tihminlioglu 2018).

Commercially, available porous scaffolds for orthopaedic applications have been made from non-degradable biomaterials. These porous bone scaffolds are intended to replace the damaged cancellous bone, with the focus on hip and knee surgery applications (Balla et al. 2010). However, compared to Fe-based and newly introduced $\mathrm{Zn}$-alloys, $\mathrm{Mg}$ and its alloys are considered to be the most suitable biodegradable metals for potential bone scaffold applications (Staiger et al. 2006; Zheng et al. 2014). Mg can be easily found in human bone tissue since its function is essential in human metabolism (Vormann 2003). Mg holds interesting mechanical properties close to those of human bone (Witte et al. 2008; Gu et al. 2009; Jasmawati et al. 2017). The structural properties of $\mathrm{Mg}$ are controllable and can be regulated precisely by constructing a porous structure with a Young's modulus that closely matches cancellous bone (0.01-2.0 GPa) (Gibson 1985; Snyder et al. 1993; Morgan and Keaveny 2001; Renders et al. 2007). The degradation of Mg-based alloys is initiated on the exposed surface area of the materials, which are immersed in a solution of chloride ions in a non-oxidising medium. These further degrade and extend to the entire surface. The deterioration of materials increases with prolonged time immersion. Usually, assessment of the degradation behaviour of porous $\mathrm{Mg}$ for bone scaffold applications is determined via static immersion tests, which is also known as the gold standard (Cheng et al. 2016). However, the dynamic immersion test has also been used, transcending the typical techniques, as it integrates the environment of fluid movement passing through cancellous bone (Md. Saad et al. 2016; Md Saad et al. 2017; Md Saad and Syahrom 2018). The degradation rate and structural properties of porous magnesium under a dynamic immersion test with a constant flow have been reported by Md. Saad et al. (2016). However, the analysis of morphological changes and growth of new tissues in the biomaterials used for bone scaffold application under such an environment has not yet been reported and thus could further contribute to the state-of-the-art research in this field.

Micro-CT is a non-destructive technique, which has the proven capability to analyse tissue engineering applications (Hedberg et al. 2005; Mistry et al. 2010; Fischerauer et al. 2013; Yu et al. 2018). The method provides a means to assess the micro-architecture of bone tissues as well as bone scaffolds, before and post-implantation (Hedberg et al. 2005; Mistry et al. 2010; Bobe et al. 2013; Feyerabend 2014). The mechanical integrity of the bone scaffold could be anticipated through the micro-CT technique, in which its morphological changes as a structural support are analysed. The mechanical strength of the bone scaffold is largely determined by its degradation behaviour, especially while 
the bone is healing (Angrisani et al. 2016). However, the micro-CT can only be used in vitro, ex vivo or in vivo for small animals (Bissinger et al. 2016).

Hypothetically, large physical changes in porous structures may cause a reduction of their structural properties (i.e. elastic modulus). Therefore, the correlation between progressive degradation due to the effect of micro-damages and structural properties can be verified through computational works, which also further strengthens results obtained from experimental works. Ideally, the porous scaffold for cancellous bone replacement should function temporarily as a buffer to the damage. In this way, the scaffold could serve to encourage the regeneration of new tissues and act as a structural support while the new tissues grow and the porous scaffold degrades. Still, the degradation time of porous $\mathrm{Mg}$ must be monitored to prevent the loss of structural support, and this could be analysed via finite element analysis. To the best of our knowledge, this study is among the first to analyse the morphological changes and structural properties of biodegradable porous $\mathrm{Mg}$ for bone scaffold application under a dynamic immersion test using the computational approach.

\section{Materials and methods}

\subsection{Production and degradation of porous $\mathrm{Mg}$}

For the purpose of this study, three types of cuboid samples $(5 \times 5 \times 3 \mathrm{~mm})$ with three different percentages of porosity $(30 \%, 41 \%$, and $55 \%)$ were used, as shown in Fig. 1. These cuboids are made from a commercially pure magnesium rod ( $25.4 \mathrm{~mm}$ diameter and $99.9 \%$ purity) obtained from Goodfellow Inc, Cambridge, UK, and fabricated using a CNC machine (HAAS, USA). The pore size of the specimen is $800 \mu \mathrm{m}$. Table 1 gives an overview of the geometries of the porous magnesium. After the fabrication process, the specimens were cleansed from any excess materials and chemicals

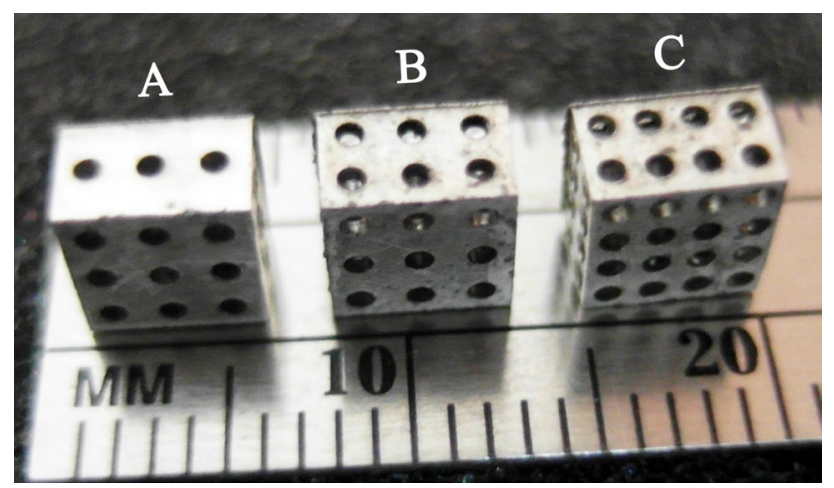

Fig. 1 The three types of porous $\mathrm{Mg}$ specimens used in this study
Table 1 Overview of the detailed geometries for the porous $\mathrm{Mg}$ specimens (Md. Saad et al. 2016; Md Saad et al. 2017)

\begin{tabular}{lllll}
\hline Type & Porosity (\%) & $\begin{array}{l}\text { Surface } \\
\text { area }\left(\mathrm{mm}^{2}\right)\end{array}$ & Volume $\left(\mathrm{mm}^{3}\right)$ & $\begin{array}{l}\text { Mass per } \\
\text { surface area } \\
\left(\mathrm{kg} / \mathrm{m}^{2}\right)\end{array}$ \\
\hline A & 30 & 189.30 & 52.87 & 0.44 \\
B & 41 & 209.81 & 44.57 & 0.34 \\
C & 55 & 225.75 & 33.83 & 0.24 \\
\hline
\end{tabular}

using air jets and an interdental brush (Tepe, USA). Prior to surface polishing, the specimens were immersed in acetone for $15 \mathrm{~min}$. The outer surfaces of the specimens were then ground using \#800 and \#1200 grit paper and then ultrasonically cleaned in acetone for $15 \mathrm{~min}$. The specimens were desiccated in a vacuum chamber for $1 \mathrm{~h}$ prior to degradation tests. The porosity of the $\mathrm{Mg}$ samples was between 30 and $55 \%$. However, the chosen porosity is shown to be comparable to cancellous bone mechanical properties to prevent stress shielding effects. Furthermore, higher porosity of porous $\mathrm{Mg}$ could lead to total lost mechanical integrity of the structure due to the fast degradation.

The porous $\mathrm{Mg}$ was subjected to a dynamic degradation test under moving simulated body fluid (SBF) at $0.025 \mathrm{~m} /$ min with $\mathrm{pH}$ and temperature levels of 7.4 and $37^{\circ} \mathrm{C} \pm 1{ }^{\circ} \mathrm{C}$, respectively (Md. Saad et al. 2016; Md Saad et al. 2017). The dynamic immersion test rig was set to have laminar flow. A peristaltic pump was used to provide a constant flow rate of $0.025 \mathrm{ml} / \mathrm{min}$ with a Reynolds number (Re) of 5.44 for the SBF throughout the 2-mm-diameter tube channel. The SBF was made of $(8.035 \mathrm{~g}) \mathrm{NaCl},(0.355 \mathrm{~g}) \mathrm{NaHCO}_{3},(0.225 \mathrm{~g})$ $\mathrm{KCl},(0.231 \mathrm{~g}) \mathrm{K}_{2} \mathrm{HPO}_{4} \cdot 3 \mathrm{H}_{2} \mathrm{O},(0.311 \mathrm{~g}) \mathrm{MgCl}_{2} \cdot 6 \mathrm{H}_{2} \mathrm{O}$, (39 ml) $\mathrm{HCl} 1.0 \mathrm{M},(0.292 \mathrm{~g}) \mathrm{CaCl}_{2},(0.072 \mathrm{~g}) \mathrm{Na}_{2} \mathrm{SO}_{4}$, and $(6.118 \mathrm{~g})$ Tris-buffer. The specimens were immersed for $24 \mathrm{~h}, 48 \mathrm{~h}$, and $72 \mathrm{~h}$. The tested specimens were then rinsed with deionised water and dried up in a vacuum chamber for $1 \mathrm{~h}$. A diluted chromic acid solution $\left(\mathrm{H}_{2} \mathrm{CrO}_{4}\right)$ was used to clean the corrosion products on the tested specimens.

\subsection{Morphological characterisation}

The mechanical testing subjected to compression test involved 36 specimens. There were three groups of porosity $(30 \%, 41 \%$, and $55 \%)$ and four groups of degradation time configurations $(0 \mathrm{~h}, 24 \mathrm{~h}, 48 \mathrm{~h}$, and $72 \mathrm{~h})$ with three replications (Md. Saad et al. 2016). Meanwhile, for the computational method, a single specimen from each group was used. The micro-CT images of the cleaned specimens $(n=12)$ were obtained using a Skyscan 1172 micro-CT device (Kontich, Belgium) at a voxel resolution of $17.2 \mu \mathrm{m}$. The micro-CT images were imported into ImageJ (Rasband, W.S., ImageJ, US National Institutes of Health, Bethesda, $\mathrm{MD}$, USA) to analyse the parameters of ratio of degraded 
volume to total volume (BV/TV), surface area, and trabecular separation (Tb.Sp).

Trabecular separation (Tb.Sp) was determined through the local thickness of the selected volumetric region (space) in between average surface-to-surface trabecular. The Tb.Sp at a single point in the porous structure is described as the diameter of the greatest sphere that corresponds within the space, which contains the point, as shown in Fig. 2. The reported Tb.Sp mean number is an arithmetic mean of the pointwise $\mathrm{Tb} . \mathrm{Sp}$ values. The arithmetic mean was calculated using ImageJ and BoneJ plugin in the trabeculae thickness section. However, in this case, the voxels representing the non-solid structure parts were filled with the greatest spheres. Thus, Tb.Sp is the average thickness of the filled cavities.

\subsection{Segmentation technique}

Greyscale images from the micro-CT images in dicom format were used to reconstruct the three-dimensional model of the specimens. The data set includes 2D images of porous $\mathrm{Mg}$ with a slice thickness of $0.172 \mathrm{~mm}$. The images were imported into Mimics software (Materialise, Belgium) to construct a 3D model of the degraded porous $\mathrm{Mg}$, as shown in Fig. 3. A region of interest (ROI) was defined and reduced as much as possible, so that the specimen would be encapsulated by the minimum number of black voxels (i.e. air). The ROI is defined by a rectangular shape of $4 \mathrm{~mm} \times 6 \mathrm{~mm}$ (larger than the cross-sectional area) and a height of $6 \mathrm{~mm}$.

The optimal threshold value is defined as that which achieves segmented volumes closest to reality or in other words, when the difference in the volumes, $V_{\text {actual }}-V_{\text {model }}$, is minimum. The optimal threshold value can be reached via a manual iterative segmentation in the Mimics Software. The flowchart of the iterative segmentation based on thresholding optimisation is shown in Fig. 4a. The porous magnesium specimen images obtained from the CT scanners consist of greyscale information. Mimics software allows the user to create 3D model based on the grey values (Hounsfield units in CT images) within these images. A grey value is a number association between the material density of the scanned object and the grey values assigned to each pixel in the image data. Because of this, Mimics (MIMICS; materialise, Louvain, Belgium) has the flexibility to create models from any geometry distinguishable within the scanned data. By grouping together similar grey values, the image data can be
Fig. 2 Trabecular separation (Tb.Sp) of Specimen A prior to the immersion test
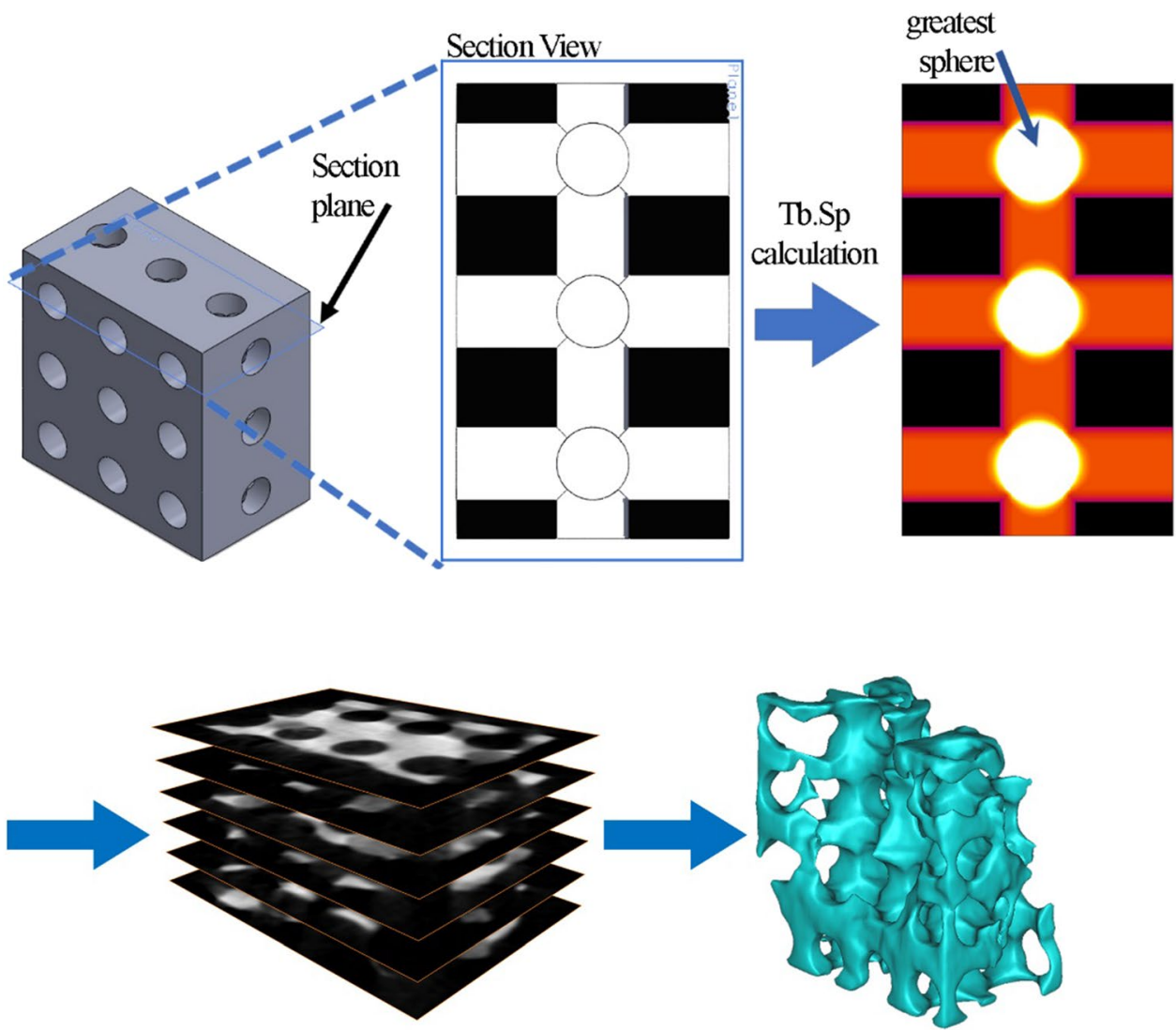

Fig. 3 3D reconstruction of Specimen C (percentage porosity of 55\%) from micro-CT images using Mimics software after $72 \mathrm{~h}$ of immersion time. The sample was scanned in air. The micro-CT scan setting was at voltage of $100 \mathrm{kV}$ with current of $100 \mathrm{uA}$, and rotation step was at $0.5^{\circ}$ 
segmented, and models can be created. This type of segmentation is called thresholding which yields accurate models. Based on the initial testing and trial-and-error, Region growing threshold-based (upper/lower) algorithm was decided to be used in this study. The unit of threshold values is Hounsfield unit (HU). In Mimics software, thresholding is used to classify all pixels within a certain Hounsfield range as the same colour or mask. Lower greyscale range was column threshold values, while upper greyscale range was $3056 \mathrm{HU}$. The final threshold used in the subsequent analysis was 725 HU. First, a range of greyscale values was chosen in order to achieve segmentation of the specimens. Next, the volume model of the specimen was set and a mask computed. The volume of the specimen must be the same as the actual model. The real volume of the scaffold after degradation $\left(V_{\text {actual }}\right)$ is known from the experimental data, for which the actual volume was calculated by dividing the scaffold mass with the pure $\mathrm{Mg}$ density $\left(1.74 \mathrm{~g} / \mathrm{cm}^{3}\right)$.

The validation stage compares the volume of the scaffold model and the actual volume. If the condition is not fulfilled, the optimisation stage, which iteratively adjusts the threshold value, is again conducted in order to obtain a model volume that matches the actual volume. This procedure is time consuming because if the greyscale chosen is not appropriate (Fig. 4b), the user will have to start over, change the range of threshold, and compute the mask again. A comparison of the 3D models from the iterative threshold is shown in Fig. 4c.

Table 2 shows a comparison of the volume determined from the CT images and the actual volume. From the results, it can be seen that the proposed iterative segmentation method provides reliable results, presenting accurate values that match the intrinsic resolution of the $\mathrm{CT}$ images.

\subsection{Degradation determination}

Degradation rate (DR) was approximated using micro-CT through the reduction in volume $(\Delta V)$, instead of using weight loss by means of experiment. The calculated volume loss from the original (prior to testing) volume to the current (after testing) volume at a particular immersion time was then converted to mass loss using the density $(\rho)$ of $\mathrm{Mg}$ $\left(1.74 \mathrm{~g} / \mathrm{cm}^{3}\right)$, resulting in the degradation rate $\left(\mathrm{mg} / \mathrm{cm}^{2} /\right.$ day $)$, as per Eq. (1):

$\mathrm{DR}=\frac{\Delta W}{A_{t}}$

where $\Delta W$ is the mass loss, $A$ is the surface area of the bone scaffold, and $t$ is the immersion time. Through the micro-CT scanning, the exact surface area was used to determine the degradation rate of the porous $\mathrm{Mg}$ which rather used area of the specimen prior to test. With this exact surface area, the in situ degradation rate could be obtained which contributes towards real condition.

\subsection{Compression test}

Compression testing was performed using a universal testing machine (The FastTrack 8874, Instron, Norwood, USA). The mechanical properties of porous $\mathrm{Mg}$ specimens before and after immersion tests were evaluated under the compression test, at a strain rate of $0.005 / \mathrm{s}$ using a $25-\mathrm{kN}$ load cell (Md. Saad et al. 2016). The elastic modulus was determined as per ASTM D1621 and ISO 13314 standards. The testing procedure for both standards was used to measure the mechanical properties of porous and cellular metals (Vesenjak et al. 2016). Three replications were done.

The reconstructed 3D models were converted to finite element meshes. Marc Mentat software (MSC Software, Santa Ana, CA) was used for finite element simulation. The 3D model of the degraded porous $\mathrm{Mg}$ was assigned homogenous, isotropic, and elastic-plastic properties. Prior to the numerical analyses, the Young's modulus of pure solid magnesium was determined by conducting compressive tests using solid samples. An average value from the compressive tests was then used as input for all numerical simulations. An ideal plasticity model was assumed for all simulations presented in the present investigation. The Young's modulus value was set to $3.5 \mathrm{GPa}$, and a Poisson's ratio of 0.35 was chosen to correspond to the properties of dense trabecular bone tissue with an apparent density of $1.74 \mathrm{~g} / \mathrm{cm}^{3}$. The model was developed with tetrahedral, pentahedral, and hexahedral elements with an average value of $(107896 \pm 9447$ elements).

The compression test was simulated via finite element method to determine the behaviour of the structure of nondegraded and degraded porous Mg. The boundary conditions used in the finite element analysis (FEA) are shown in Fig. 5. A time-dependent displacement boundary condition was defined on the top surface to simulate the moving platen of an experimental test rig. Time-dependent boundary conditions refer to the nodes assigned on the top surface to be solved in a finite domain. In addition, a zero-displacement boundary condition was assigned to the opposite surface in its normal direction, simulating a stationary compression platen. Nodes included in this boundary condition were confined only in the y-direction but were allowed to move freely inside the $x-z$ plane. The macroscopic compression strain limit was set to $\varepsilon=0.3$ for the computational tests. A plastic strain of $30 \%$ was chosen for the scope of this study since plasticity is predicted to occur within the specified plastic strain range.

\subsection{Statistical analysis}

Statistical analyses were performed using IBM SPSS Statistics 23 (IBM Corp, USA). Pearson's correlation test was conducted to predict the structural properties of porous $\mathrm{Mg}$ 


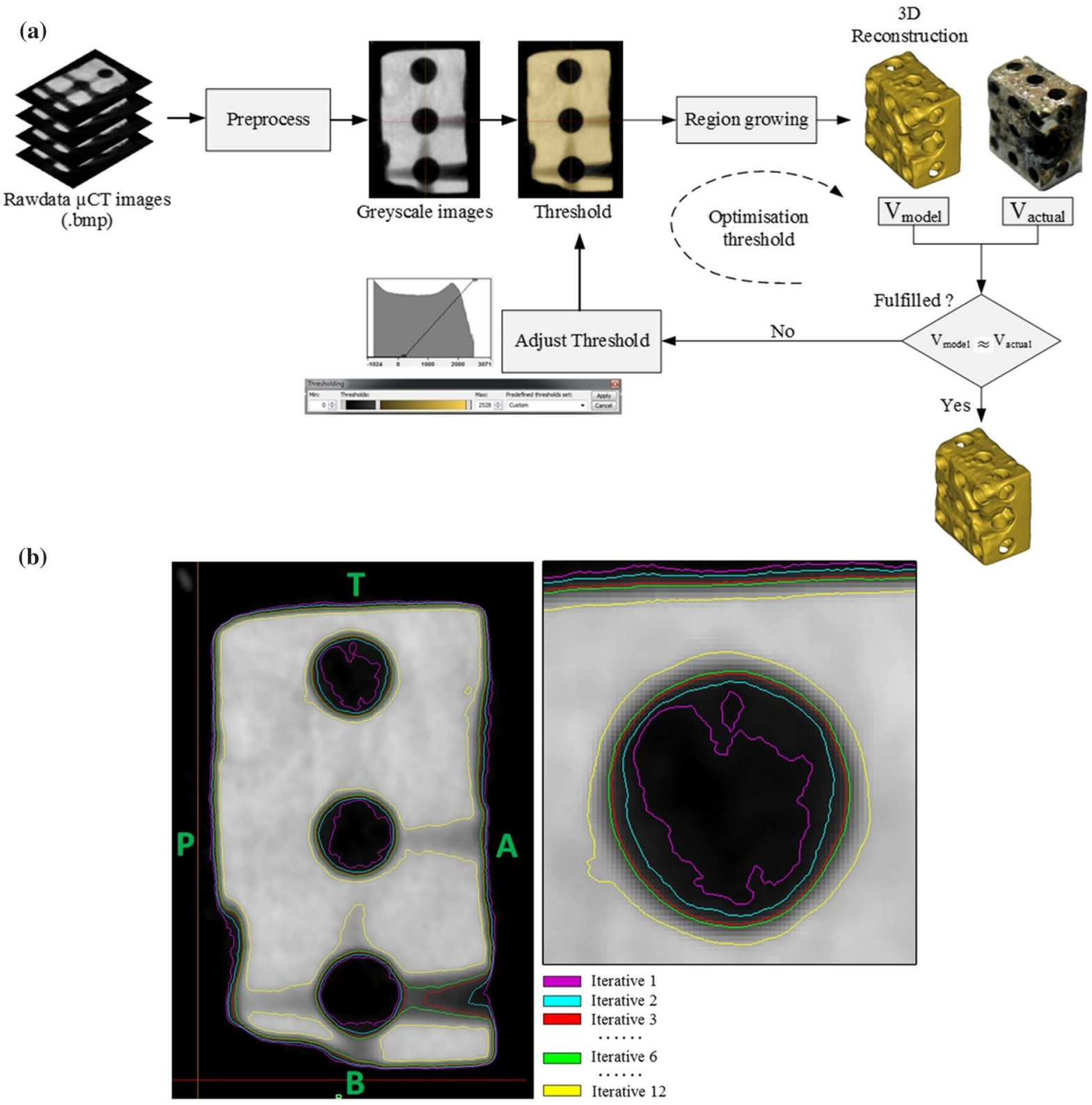

(c)

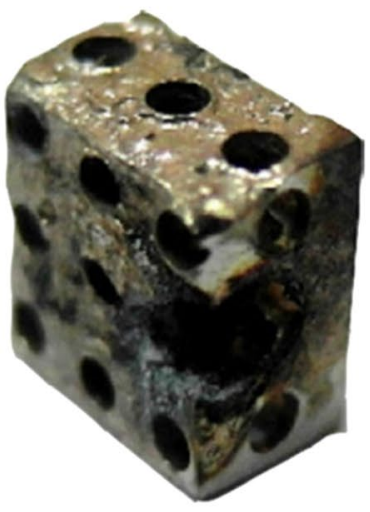

Actual Sample

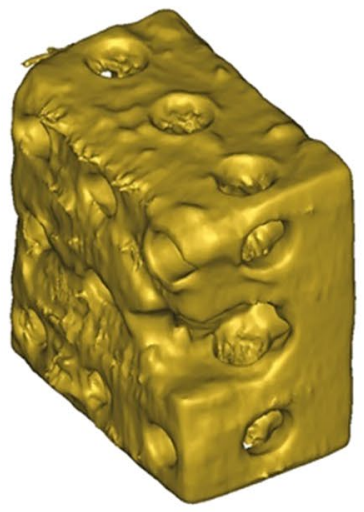

\# Iterative 1

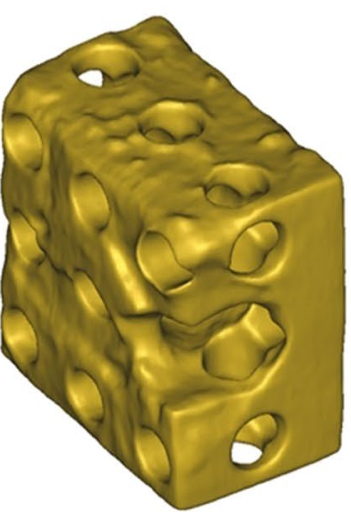

\# Iterative 6

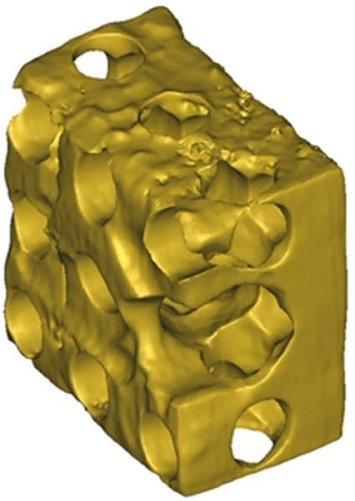

\# Iterative 12 
४Fig. 4 Iterative segmentation: a flowchart of the iterative segmentation based on thresholding optimisation, $\mathbf{b}$ an example of the scaffold model segmentation based on the iterative thresholding method in Mimics software, and $\mathbf{c}$ a comparison of the 3D models from the iterative threshold

by volume fraction (BV/TV), bone surface area, and trabecular separation (Tb.Sp).

\section{Results}

\subsection{Degradation characterisation}

Figure 6 shows the degradation of the porous $\mathrm{Mg}$ specimen which was determined using micro-computed tomography measurement. Figure 6a shows the relative volume loss of porous $\mathrm{Mg}$ with increased percentage difference in porosity as the time of immersion increased. The loss of volume in the specimen increased as the percentage of porosity increased. Figure $6 \mathrm{~b}$ demonstrates the relative surface area loss of the specimen, which increased as the time of immersion increased. The specimen with a higher percentage of porosity shows a huge loss of surface area compared to others. The loss of surface area curve for Specimens A and B shows a similar trend, in which the increment in surface area loss gradually decreased as time of immersion increased. Meanwhile, Specimen C was observed to lose more surface area as immersion time increased. Figure $6 \mathrm{c}$ shows the degradation rate of the porous $\mathrm{Mg}$ specimen with different percentages of porosity using original surface area. After $24 \mathrm{~h}$ of immersion time, Specimen B showed a higher degradation rate followed by Specimens $\mathrm{C}$ and A. Meanwhile, after $48 \mathrm{~h}$, all specimens showed almost similar degradation rates. After $72 \mathrm{~h}$, Specimen C showed the highest degradation rate followed by Specimens B and A. Figure 6d shows the degradation rate of specimens with different percentages of porosity, which were calculated using surface area and determined by micro-CT measurement at their respective immersion time. The degradation rate of Specimen $\mathrm{C}$ was higher after a 24-h immersion time, followed by Specimens $\mathrm{B}$ and A, which showed a similar trend after 48 and $72 \mathrm{~h}$. Meanwhile, after $72 \mathrm{~h}$, the degradation rate of Specimen C increased compared to the other specimens, which saw a decrease.

\subsection{Mechanical characterisation}

Figure 7a shows the elastic modulus of the specimens determined by experiment and simulation. The elastic modulus determined by simulation is in good agreement with the experiment, in which all samples showed a clear downward trend in modulus value with increasing porosity percentage and immersion time. Figure $7 \mathrm{~b}$ shows a comparison of compressive stress-strain curves between the experimental and finite element simulation for Specimen A prior to the immersion test (A0). The relative modulus was based on the slope of the stress-strain curve. The modulus for experiment and simulation was $1991 \mathrm{MPa}$ and $2016 \mathrm{MPa}$, respectively. When the strain exceeded 0.05 , the experimental data dropped significantly and vice versa for the simulation. Figure 8 demonstrates the principal elastic strain of the specimens with different percentages of porosity after the dynamic immersion test under a uniaxial compression test. Specimen A shows an oblique fracture at $45^{\circ}$, while Specimens $\mathrm{B}$ and $\mathrm{C}$ experienced global fracture. From Fig. 8, the experimental results and predictions from FEA were also compared within the same group of specimen morphologies. It can be concluded that elastic strain from the FEA results suggests a similar collapsing pattern indicated by red dashed lines. It is interesting to note that some simulation results are slightly above the range of experimental data. This may be explained by the fact that numerical models are selected from one of three specimens used for the experimental tests. In the case of B24, for example, the numerical simulations overpredicted the elastic modulus for this group sample's morphology.

\subsection{Morphological characterisation}

Figure 9 shows the charts of morphological changes of porous $\mathrm{Mg}$ after being subjected to the dynamic immersion test up to $72 \mathrm{~h}$. Figure 9a shows the volume fraction changes in the specimens. The volume fraction of each specimen was seen to decrease over time. After a 72-h immersion time, the percentage of porosity ( 1 -volume fraction) for Specimens A (30\%), B (41\%), and C (55\%) increased to $50 \%, 53 \%$, and $72 \%$, respectively. Figure $9 \mathrm{~b}$ illustrates the changes in surface area of porous $\mathrm{Mg}$ for each specimen, which decreased as immersion time increased. The surface area of Specimens A and B gradually decreased by $17 \%$ and $22 \%$, while Specimen $\mathrm{C}$ showed an abrupt decrease in surface area by $44 \%$, after the 72 -h immersion time. Figure 9c shows the changes in trend for trabecular separation in each specimen, which increased as immersion time increased. After the 72-h immersion time, the trabecular separation changes for Specimens A, B, and C were $47 \%, 46 \%$, and $69 \%$, respectively.

\subsection{Mechanical degradation}

Figure 10 shows the correlation between elastic modulus and morphological parameters of porous $\mathrm{Mg}$ before and after being subjected to tests. The elastic modulus from the simulation was used to analyse any correlation with specimen morphology. The morphological parameters acquired from the micro-CT analyses are volume fraction (BV/TV), 
Table 2 Summary of the virtual model created with manual iterative threshold segmentation

\begin{tabular}{lrlll}
\hline Iterative & $\begin{array}{l}\text { Threshold } \\
\text { values (HU) }\end{array}$ & $\begin{array}{l}\text { Volume of Mim- } \\
\text { ics model }\left(\mathrm{mm}^{3}\right)\end{array}$ & $\begin{array}{l}\text { Actual } \\
\text { volume } \\
\left(\mathrm{mm}^{3}\right)\end{array}$ & $\begin{array}{l}\text { Percent- } \\
\text { age error } \\
\%\end{array}$ \\
\hline$\# 1$ & -592 & 50.58 & 39.89 & 26.82 \\
$\# 2$ & -407 & 46.32 & 39.89 & 16.13 \\
$\# 3$ & 0 & 41.61 & 39.89 & 4.33 \\
$\# 4$ & 110 & 40.57 & 39.89 & 1.72 \\
$\# 5$ & 150 & 40.19 & 39.89 & 0.77 \\
$\# 6$ & 186 & 39.87 & 39.89 & 0.03 \\
$\# 7$ & 200 & 39.73 & 39.89 & 0.39 \\
$\# 8$ & 240 & 39.41 & 39.89 & 1.19 \\
$\# 9$ & 267 & 39.16 & 39.89 & 1.82 \\
$\# 10$ & 300 & 38.89 & 39.89 & 2.49 \\
$\# 11$ & 1076 & 32.53 & 39.89 & 18.53 \\
$\# 12$ & 1416 & 28.83 & 39.89 & 27.72 \\
\hline
\end{tabular}

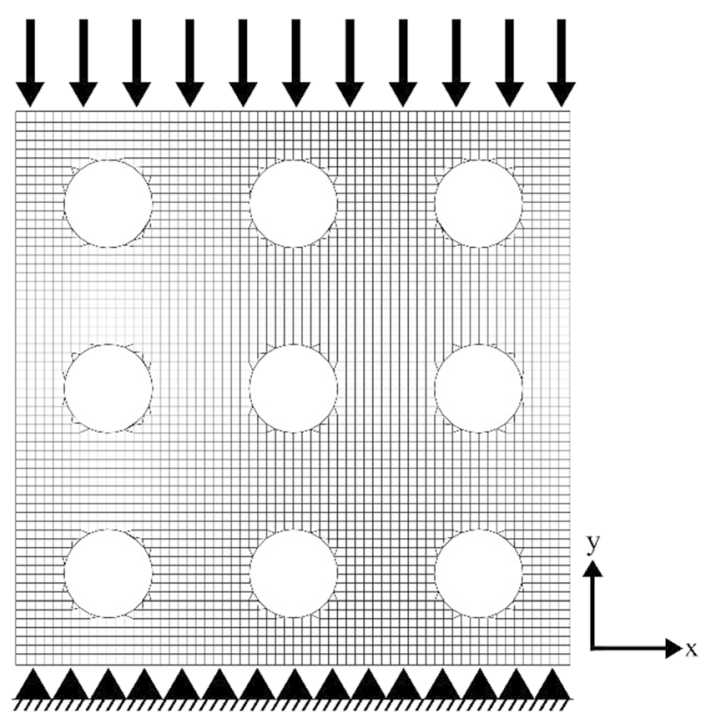

Fig. 5 Boundary conditions applied on the porous $\mathrm{Mg}$

surface area, and trabecular separation (Tb.Sp). Figure 10a shows the correlation between the elastic modulus and volume fraction ( 1 - porosity) of the specimens. The specimens with a higher volume fraction demonstrated a higher elastic modulus. As the time of immersion increased, the volume fraction as well as the elastic modulus for all specimens decreased in an orderly manner. The volume fraction of Specimens B and C showed a sudden drop based on the steep slopes as compared to Specimen A, which gradually decreased. The volume fraction of Specimen C was greatly reduced after $72 \mathrm{~h}$, thus resulting in a low elastic modulus. From the statistical analyses, volume fraction significantly impacted elastic modulus with a $p$ value $<0.005$ and the correlation coefficient, $r$, between volume fraction and elastic modulus was 0.94 .

Figure 10b shows the correlation between elastic modulus and surface area of the specimen. The surface area for all specimens decreased in an orderly manner as time of immersion increased, which resulted in a decrease in elastic modulus. Specimens A and B showed almost a similar decline pattern compared to Specimen C. The gradual decrease in surface area after 24-h immersion time resulted in smallest changes in elastic modulus as compared to specimens that demonstrated a huge loss in surface area. From the statistical analyses, surface area significantly impacted elastic modulus with a $p$ value $<0.005$ and the correlation coefficient between surface area and elastic modulus was 0.57 .

Figure 10c shows the correlation between elastic modulus and trabecular separation of the specimen. The trabecular separation for all specimens increased in an orderly manner, resulting in elastic modulus to decrease accordingly. The initial value of trabecular separation for all specimens was almost similar; however, the result was different for elastic modulus. The large changes in trabecular separation for Specimen $\mathrm{C}$ correlated with a huge drop in elastic modulus after the 72-h immersion time. From the statistical analyses, trabecular separation significantly impacted elastic modulus with a $p$ value $<0.005$ and the correlation coefficient between trabecular separation and elastic modulus was -0.85 .

\section{Discussion}

Porous $\mathrm{Mg}$ is suggested to be used as cancellous bone replacement due to its mechanical properties, which is almost equivalent to cancellous bone properties. The nature of the cancellous bone environment promotes bone remodelling to happen provided that physiological activity also occurs. This activity induces pressure differentials on the bone, causing the bone marrow to flow. The movement of the bone marrow passing through the porous structure triggers mechanical stress through mechanobiological signalling that activates bone remodelling process and preserves bone quality. This is why, once porous $\mathrm{Mg}$ is implanted, it will be exposed to the cancellous bone environment and will not only serve as a device to enhance tissues growth, but also most importantly to act as a load-bearing structure during the bone healing process. The dynamic degradation of porous $\mathrm{Mg}$ under the simulated human cancellous bone environment has been reported elsewhere (Md. Saad et al. 2016). However, there are some parameters such as morphological parameters that cannot be fully obtained through experimental works. Therefore, micro-CT measurement was used to obtain the comprehensive mechanical characteristics of porous $\mathrm{Mg}$ as a load-bearing structure. Degradation rate 

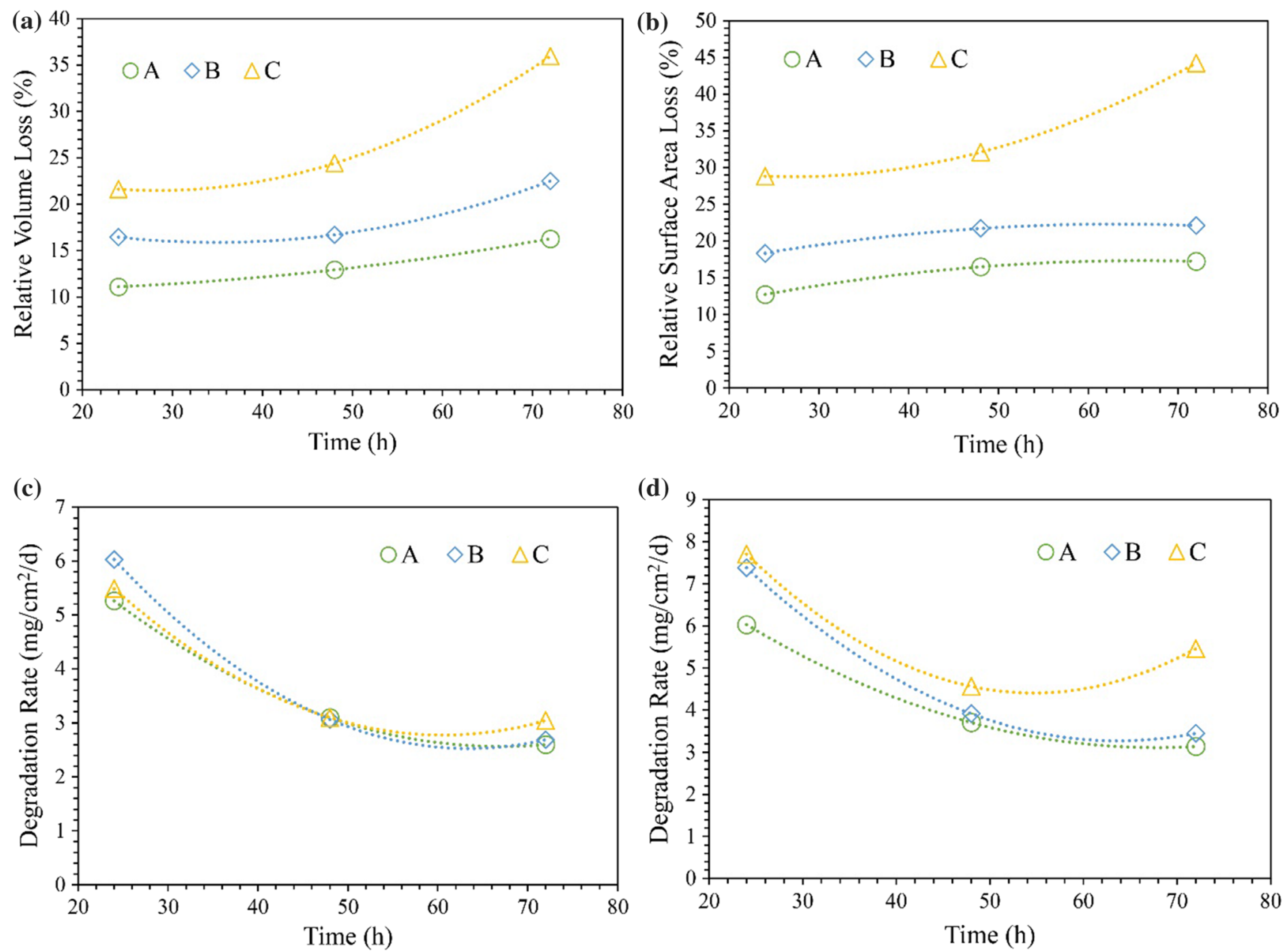

Fig. 6 Degradation characterisation: a relative volume loss (\%), b relative surface area loss (\%), $\mathbf{c}$ degradation rate of specimens using original surface area, and $\mathbf{d}$ degradation rate of specimens using degraded surface area

by means of micro-CT determination is a non-destructive measurement technique useful, especially for clinical use. Besides being advantageous for clinical use, this technique also enables the acquisition of morphological parameters, which may be impossible to obtain through experimental works. In addition, the growth rate of the new tissue matrix can also be identified using this technique. Hence, the morphological index effects such as volume fraction (BV/TV), bone surface area, and trabecular separation (Tb.Sp) on elastic modulus of porous $\mathrm{Mg}$ can be determined. However, this method is costly.

Relative volume loss determined by the micro-CT analysis, as shown in Fig. 6a, demonstrates that relative volume loss increases as the time of immersion increases, whereby the specimen with a higher percentage of porosity indicates greater volume loss compared to others. The pattern of volume loss is in agreement with relative mass loss reported elsewhere (Md. Saad et al. 2016). In this study, the reconstructed volume for the specimens in the experimental works was similar. For the volume loss, it is relative to specimens prior to degradation test. However, in this paper, losses were calculated relative to the specimens prior to degradation which was different from the experiments that calculated mass loss. The percentage of volume loss was calculated by volume difference from sample A at $0-48 \mathrm{~h}$. The missing part is the actual sample specimen at $0 \mathrm{~h}$. Fabrication techniques and cleaning procedure were standardised causing the scanned specimen at $0 \mathrm{~h}$ to be the same. It is believed that the scanned prior degradation specimen is in range with the experiments that calculate mass loss. However, there must be small deviation when compared to mass loss. Meanwhile, through the micro-CT analysis, the loss of surface area could also be measured after the specimen was subjected to the dynamic degradation test, which might have been impossible to obtain through experimental works (Feyerabend 2014). As presented in Fig. 6b, the relative surface area loss increases as the time of immersion increases; the percentage of porosity also increases. The larger the exposed surface 

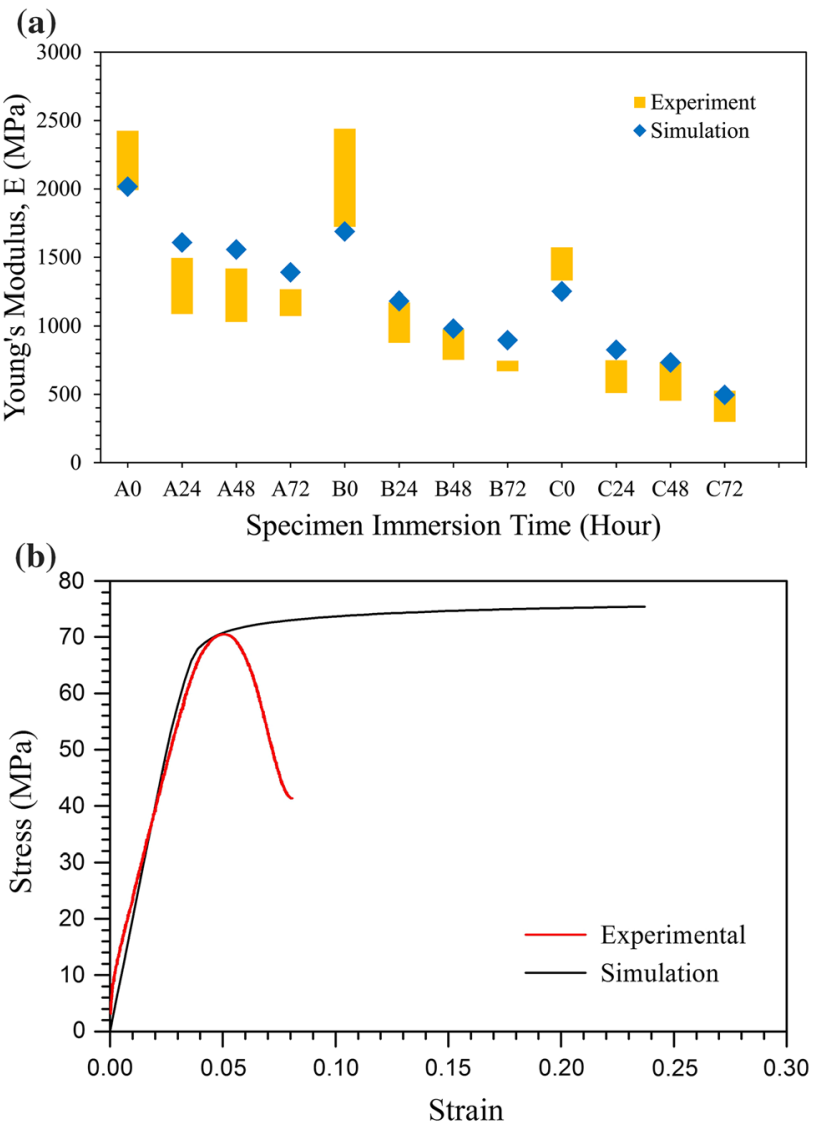

Fig. 7 a Elastic modulus of the specimens determined by experiment and simulation (Md. Saad et al. 2016) and b Comparison of compressive stress-strain curves between the experimental and finite element simulation for Specimen A prior to the immersion test (A0). Specimen A prior to the immersion test (A0). The range of modulus experimental values for specimen A0, A24, A48 and A72 h was as follows (2425-1991 MPa), (1494-1087 MPa), (1416-1029 MPa), and (1266-1072 MPa), for specimens B0, B24, B48, and B72 was (2439$1723 \mathrm{MPa}),(1173-876 \mathrm{MPa}),(977-751 \mathrm{MPa})$ and (746-668 MPa) and for specimens $\mathrm{C} 0, \mathrm{C} 24, \mathrm{C} 48$, and C72 was (1572-1330 MPa), (749-509 MPa), (734-454 MPa), and (526-298 MPa), respectively

area of $\mathrm{Mg}$ to the fluid medium, the faster the degradation process in proportion to the surface contact available (Bobe et al. 2013). A significant trend in the loss of surface area for Specimen $\mathrm{C}$ after the $72 \mathrm{~h}$ of immersion time was identified due to the larger surface contact which resulted in more degradation than the others. Figure $6 \mathrm{c}$ and $\mathrm{d}$ shows the degradation rate of porous $\mathrm{Mg}$ determined by micro-CT; however, the difference between them is the surface area used, which are the original and degraded surface areas, respectively. Both degradation rate trends demonstrate agreement with the previous work (Md. Saad et al. 2016). The degradation rate using original surface area obtained in this study (Fig. 6c) shows a slightly different pattern compared to previously reported work using weight loss measurement. After the 24-h immersion time, Specimen B degraded faster compared to Specimen $\mathrm{C}$ and all the specimens showed similar degradation rates after the 48 -h immersion time. In contrast, degradation rates using exact (degraded) surface area at a particular time (Fig. 6d) demonstrated an average degradation rate of $20 \%$ higher than the original surface area (Fig. 4c). Therefore, predictions that take into account the use of actual surface area will result in higher degradation rates. In terms of accuracy, the degradation rate calculation must include the actual value of surface area, so that the real in situ degradation rate can be obtained (Bobe et al. 2013).

This present study uses twelve specimens by measuring their morphological parameters using micro-CT scan, and mechanically characterising the specimens using FEA. The obtained compression test results were then validated with experimental works (Md. Saad et al. 2016). Figure 7a demonstrates the range of experimental value and the point of simulation results for the compression test. The elastic modulus from the experimental work was in line with simulation. This shows that the prediction of structural properties through FEA can be used to predict the correlations between the structural properties and morphological parameters of degraded porous $\mathrm{Mg}$. The simulation data show an underestimated elastic modulus at $t=0$, and closely overestimated elastic modulus from experimental data at $t=24$, 48,72 , which is caused by the segmentation of the degradation model. Although the percentage error was close to the real structure, it was anticipated that the complexity of the degradation model to be altered, where a specific region, especially the thin strut of the degraded region, indicated the inclusion of error (overlapping) elements. Meanwhile, Fig. 7b shows good agreement between experimental and simulation data for up to 0.05 strain. Elastic modulus for both conditions was $1991 \mathrm{MPa}$ and $2016 \mathrm{MPa}$, respectively. The slope of the elastic region for the simulation was steeper than the experimental model. This shows that the simulation model was very threshold dependent, while the experimental model was not although both moduli coincided. However, beyond that, the theoretical stress-strain curve significantly dropped due to plastification and fracture (break) from the experimental work because porous $\mathrm{Mg}$ is a brittle material. The simulation curve gradually increased (known as the plateau region) past the 0.05 strain. This is because the FE software only considered the yield strength of the material acquired from the experimental data. Therefore, the fracture was not taken into account and the stress increased up to 0.3 strain. FEA of bone scaffold for bone regeneration has been extensively studied (Lacroix et al. 2009; Milan et al. 2009; Planell et al. 2009; Boccaccio et al. 2010; Williams and Mccullough 2017; Uth et al. 2017). Uth et al. (2017) reported that the experimental modulus, designed experiment predicted modulus, and COMSOL predicted modulus of the bone scaffold modelled are $5.07 \pm 0.17 \mathrm{MPa}$, 8.50 MPa, and 6.09 MPa, respectively. The overestimated 
Fig. 8 Contour plots of the fracture patterns after dynamic immersion test: a specimen A, b specimen $\mathrm{B}$, and $\mathbf{c}$ specimen $\mathrm{C}$, and principal plastic strain contours from FEA: d specimen A, e specimen $B$, and $\mathbf{f}$ specimen C. All specimens were tested after $48 \mathrm{~h}$ of immersion
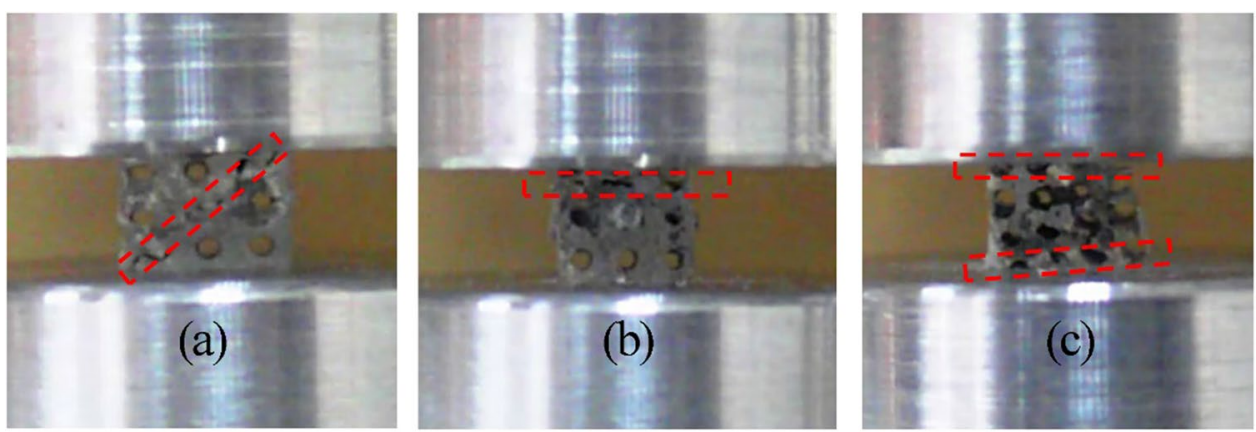

Principal elastic strain
0.15

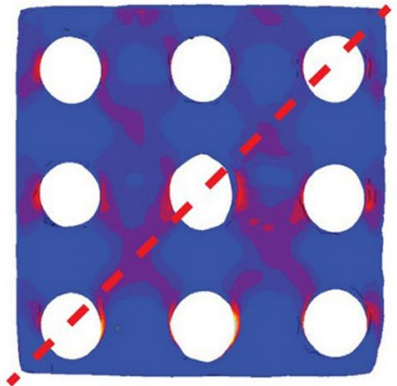

(d)

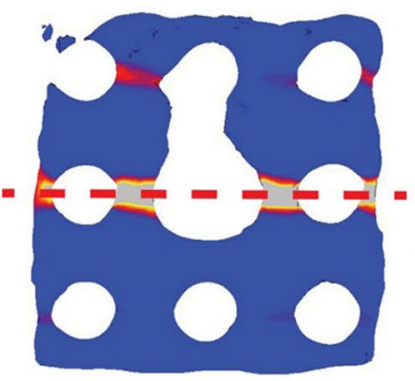

(e)

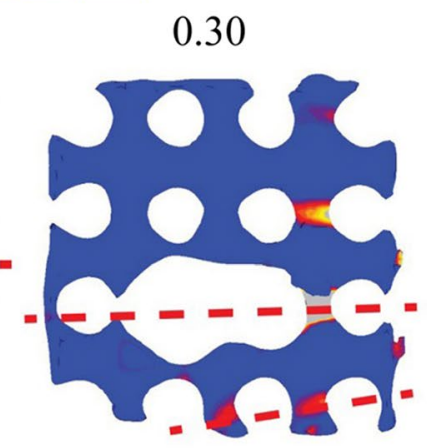

(f) difference between experimental and predicted moduli is $67 \%$ and $20 \%$. The modulus of this bone scaffold was very low as compared to cancellous bone modulus in the range of 0.05-25.9 MPa. However, in the present study, the porous $\mathrm{Mg}$ either before or after degradation has shown comparative modulus towards the cancellous bone structure.

The fracture line of porous $\mathrm{Mg}$ after the dynamic immersion test, as shown in Fig. 8, indicates that there are two types of fracture: oblique and global. Oblique fracture can be observed in Specimen A from both the experimental and FEA analyses of the magnesium scaffold structures. This type of fracture mode may be attributed to the ductility of the material. Plastification continues to form a band of collapse as it travels to randomly weak regions. For Specimen A, an oblique fracture was observed in the experimental tests and FEA simulation. A collapse band of $45^{\circ}$ can be seen from Fig. 6a and d. In addition, a study reported that most cancellous bone generally have global fractures; however, there are still some cancellous bone specimens that have oblique and local fractures (Syahrom et al. 2011). The random alteration of porous $\mathrm{Mg}$ due to degradation has caused large changes to the specimen with a higher percentage of porosity. The localised degradation has weakened the struts of the specimen, which was identified to cause Specimen C (Fig. 8c) to show a two-line fracture. This fracture is associated with high trabecular separation, as shown in Fig. 9c (Perilli et al. 2008). This information is crucial in applying the bone scaffold for load-bearing purpose. The fracture characteristic is similar to actual cancellous bone, which could represent the damage behaviour of the scaffold once implanted to prevent different directional stress effects.

The alteration to the structure due to degradation mechanism has caused significant changes to the morphological indices of porous $\mathrm{Mg}$ as immersion time increases, as shown in Fig. 9. These changes are important to predict the reduction in structural properties of porous $\mathrm{Mg}$ as bone scaffold serves as a load-bearing structure while bone heals and new tissues form. The volume fraction, surface area, and trabecular separation of the specimen were significantly correlated over immersion time. The specimen with a higher percentage of porosity was vulnerable to greater morphological changes due to dynamic degradation mainly because of the larger surface area contact. However, it is not typical for a porous specimen with a higher percentage of porosity to directly correlate with a high surface area. As reported by Syahrom et al. (2013), a porous specimen usually has a similar percentage of porosity with different surface areas due to the design of its morphological structure.

The effects of morphological changes on the elastic modulus are shown in Fig. 10. All morphological parameters were reduced significantly after the 24-h immersion time, except for Specimen $\mathrm{C}$, which showed gradual reduction after $72 \mathrm{~h}$. This is related to the rigorous degradation process that occurs in the first 24-h immersion time. This results in shrinkage of structure and reduces the effective modulus. As the time prolongs, the passive layer built up 

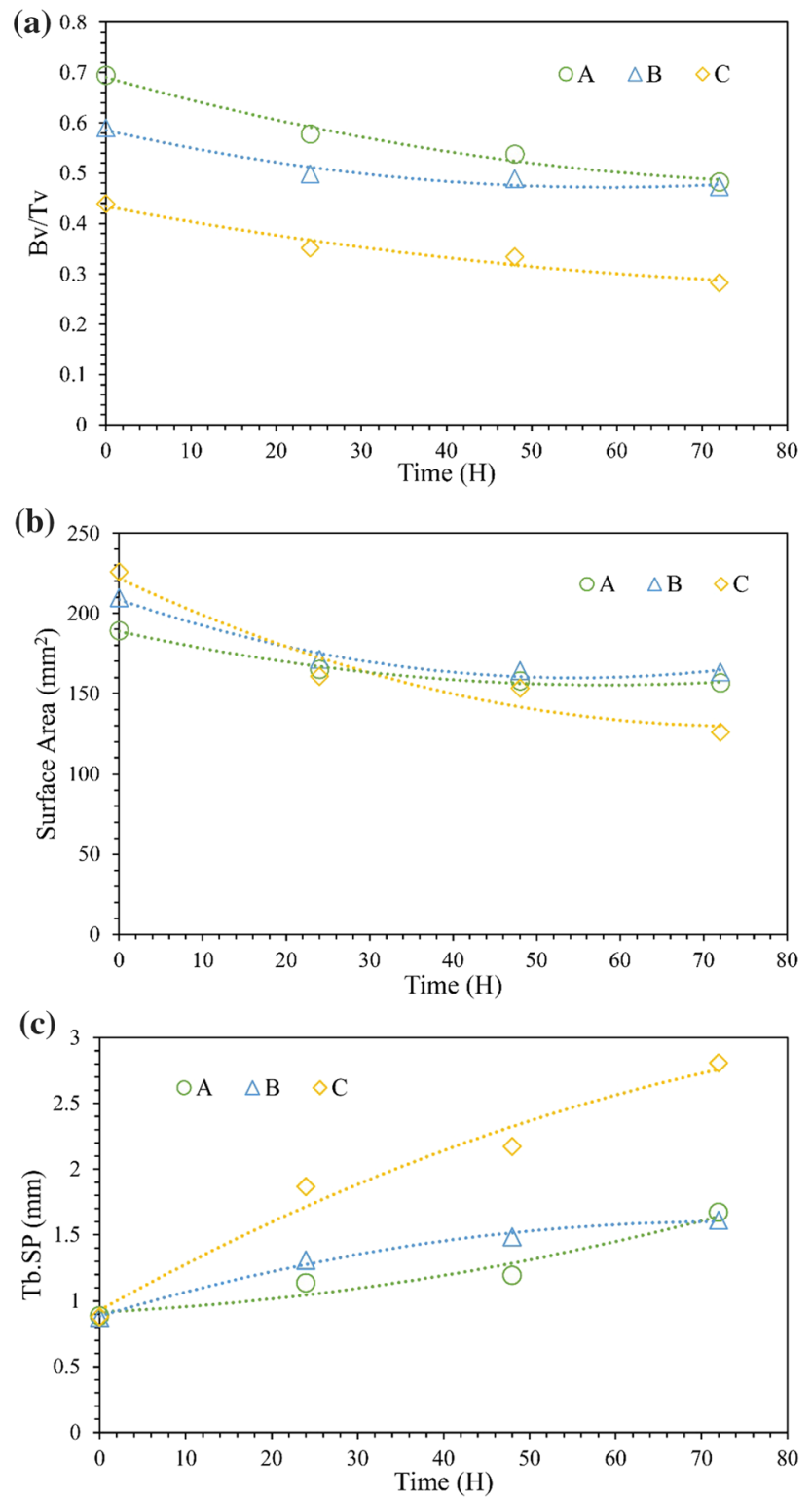

Fig. 9 Morphological changes in porous Mg under dynamic degradation test: a volume fraction (BV/TV), b surface area, and $\mathbf{c}$ trabecular separation (Tb.Sp)

on top of the surface slows down the degradation rate, resulting in a slight change in structure (Md Saad et al. 2017). The morphological parameters such as volume fraction, surface area, and trabecular separation had a strong correlation with elastic modulus, as demonstrated in Fig. 10a, b, and d (Syahrom et al. 2011). The current condition is not suitable for cancellous bone replacement due to its materials itself. However, it is believed that a suitable coating to increase the pure $\mathrm{Mg}$ corrosion resistance is enough than alloying element. This is because in terms of structural properties, porous $\mathrm{Mg}$ has shown to be a match with cancellous bone. The appropriate structural
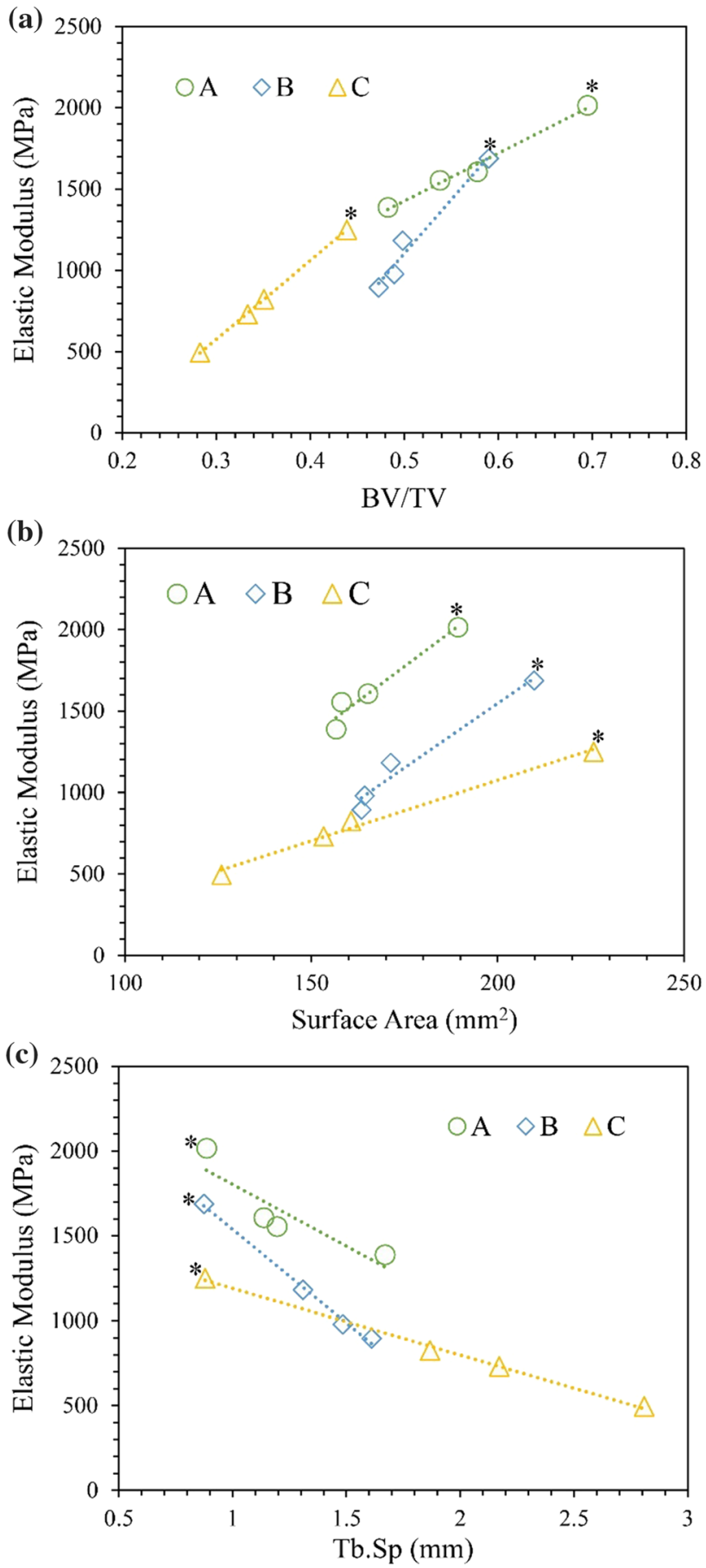

Fig. 10 Correlation between elastic modulus and morphological parameters: a volume fraction (BV/TV), b surface area, and $\mathbf{c}$ trabecular separation (Tb.Sp). (Note: * denotes the specimen before being subjected to the test)

properties to cancellous bone are crucial to prevent stress shielding effects which could lead to other complications. The only thing to be modified is the corrosion resistance through coating so that the porous $\mathrm{Mg}$ could serve as biodegradable metal which is a temporary device for 
tissue regeneration and structural support for load-bearing purposes.

The porous $\mathrm{Mg}$ geometry that is present in this study is basically the idealised structure for cancellous bone replacement. There are several types of geometry for bone scaffold application using biodegradable metal that depend on their manufacturing process. The open porous scaffold of the Mg alloy AZ91D was processed using the negative salt $(\mathrm{NaCl})$ pattern moulding, and their percentage of porosity was $72-76 \%$ (Witte et al. 2007a, b). The honeycomb structure of porous $\mathrm{Mg}$ was fabricated using laser perforation technique to obtain highly ordered porous structure with a porosity percentage of $48 \%$ (Geng et al. 2009). The open porous Mg scaffolds were fabricated using the titanium wire space holder (TSWH) method which had a porosity percentage of 55\% (Cheng et al. 2016). Porous $\mathrm{Mg}$ scaffold which was fabricated with $\mathrm{Mg}$ fibres was lined up perpendicular to each other to form network structure unit. Fifteen network structure units were layered, and then hot pressing was used to bind the fibres to one another. This technique is known as fibre deposition hot pressing (FDHP) for fabricating porous $\mathrm{Mg}$ scaffolds which had 33-54\% percentage of porosity (Zhang et al. 2014). The lotus type of porous $\mathrm{Mg}$ was fabricated using metal/gas eutectic unidirectional solidification method (Gu et al. 2010). The lotus type of porous $\mathrm{Mg}$ had ordered and aligned long cylindrical pores with $28 \%$ of porosity. Furthermore, the ordered and controllable porous structure techniques for Young's modulus of the porous $\mathrm{Mg}$ can be controlled precisely by adjusting the porosity and arranging the pores (Bose et al. 2012; Jiang and He 2014). In this study, the mechanical properties of porous $\mathrm{Mg}$ have been matched with the cancellous bone structure. However, the porous $\mathrm{Mg}$ geometry can be improved through controllable porosity as well as surface area using new fabrication techniques such as additive manufacturing. This technique improves the porous $\mathrm{Mg}$ geometry for nutrient transport and bone remodelling. It is significant that $\mathrm{Mg}$ is important to many physical functions (Castiglioni et al. 2013). In fact, the degradation products of $\mathrm{Mg}$ produce a good hydroxyapatite product for bone formation (Bigi et al. 1993). The main concern for porous $\mathrm{Mg}$ to become a reliable bone scaffold to be used in clinical studies is their low corrosion resistance which leads to fast degradation (Bobe et al. 2013). The state of the art of the bone scaffold made of $\mathrm{Mg}$ is that it not only serves as a temporary device to encourage new bone formation but also acts as a structural support for load-bearing purposes. The fast degradation leads the scaffold to beat its purposes. This shows that the coating to porous $\mathrm{Mg}$ would ensure better scaffolding. Coating materials such as polycaprolactone/ bioactive glass composite (Yazdimamaghani et al. 2015) and calcium-orthophosphate (Dorozhkin 2014) are among widely used. Therefore, it is important for porous to have surface modification to prolong the degradation time and structural integrity.

The study is subjected to some limitations. One limitation is that the micro-CT measurement of each specimen was not repeated. The study obtains a set of micro-CT data of twelve specimens. Selection of specimen from one group (for example, after the 24-h immersion time) was taken randomly by assuming that their degradation was almost similar from the macro-level perspective. This is where computer simulation is preferred because it does not cost as much as micro-CT measurements. However, the model constructed from the greyscale images is dependent on the threshold. The optimum threshold attained depends on the greyscale images (Enyedi et al. 2005). Therefore, the best techniques to provide data which are closer to the experimental data are the adaptive methods.

\section{Conclusion}

The present study evaluates the relationship between morphological changes and structural properties of porous $\mathrm{Mg}$ using dynamic immersion test. A micro-CT technique was used to quantitatively measure the degradation rates and morphological changes of porous Mg. From the scanned data scan, 3D models were reconstructed and their structural properties were analysed using FEA. The correlation between the obtained structural properties and morphological parameters was identified, and their level of significance was investigated. The degradation rates determined using exact (degraded) surface area at particular immersion times (Fig. 6d) were on average 20\% higher than the degradation rates obtained using original surface area. Dynamic degradation is shown to significantly impact the morphological changes of porous $\mathrm{Mg}$ such as volume fraction, surface area, and trabecular separation with $p$ values $<0.005$. This in turn affects the structural properties of porous $\mathrm{Mg}$. Finally, through micro-CT scan, degradation determination becomes closer to the real conditions. Using the exact surface area, the in situ degradation rate can be obtained which will contribute to the real condition.

Acknowledgements This project was sponsored by Universiti Teknologi Malaysia (UTM) via the Potential Academic Staff (PAS) Grant scheme (Q.J130000.2724.03K09). The authors would like to thank the Research Management Centre, Universiti Teknologi Malaysia (UTM), for managing the project. Several authors of this present study are financially supported by the HIR-MOHE research grant initiative.

\section{Compliance with ethical standards}

Conflict of interest The authors declare no conflict of interest. 


\section{References}

Angrisani N, Reifenrath J, Zimmermann F et al (2016) Biocompatibility and degradation of LAE442-based magnesium alloys after implantation of up to 3.5 years in a rabbit model. Acta Biomater 44:355-365. https://doi.org/10.1016/J.ACTBIO.2016.08.002

Balla VK, Bodhak S, Bose S, Bandyopadhyay A (2010) Porous tantalum structures for bone implants: fabrication, mechanical and in vitro biological properties. Acta Biomater 6:3349-3359. https ://doi.org/10.1016/j.actbio.2010.01.046

Bigi A, Falini G, Foresti E et al (1993) Magnesium influence on hydroxyapatite crystallization. J Inorg Biochem 49:69-78. https ://doi.org/10.1016/0162-0134(93)80049-F

Bissinger O, Kirschke JS, Probst FA et al (2016) Micro-CT vs. whole body multirow detector $\mathrm{CT}$ for analysing bone regeneration in an animal model. PLoS ONE 11:1-15. https://doi.org/10.1371/journ al.pone. 0166540

Bobe K, Willbold E, Morgenthal I et al (2013) In vitro and in vivo evaluation of biodegradable, open-porous scaffolds made of sintered magnesium W4 short fibres. Acta Biomater 9:8611-8623. https://doi.org/10.1016/j.actbio.2013.03.035

Boccaccio A, Ballini A, Pappalettere C et al (2010) Finite element method (FEM), mechanobiology and biomimetic scaffolds in bone tissue engineering. Int J Biol Sci 7:112-132

Bose S, Roy M, Bandyopadhyay A (2012) Recent advances in bone tissue engineering scaffolds. Trends Biotechnol 30:546-554. https ://doi.org/10.1016/j.tibtech.2012.07.005

Castiglioni S, Cazzaniga A, Albisetti W, Maier JAM (2013) Magnesium and osteoporosis: current state of knowledge and future research directions. Nutrients 5:3022-3033. https://doi.org/10.3390/nu508 3022

Cheng M, Wahafu T, Jiang G et al (2016) A novel open-porous magnesium scaffold with controllable microstructures and properties for bone regeneration. Sci Rep 6:24134. https://doi.org/10.1038/ srep24134

Dorozhkin SV (2014) Calcium orthophosphate coatings on magnesium and its biodegradable alloys. Acta Biomater 10:2919-2934. https ://doi.org/10.1016/j.actbio.2014.02.026

Enyedi B, Konyha L, Fazekas K (2005) Threshold procedures and image segmentation. In: 47th international symposium ELMAR, 2005. IEEE, pp 29-32

Feyerabend F (2014) Biomaterials for bone regeneration. Woodhead Publishing Limited, Sawston

Fischerauer SF, Kraus T, Wu X et al (2013) In vivo degradation performance of micro-arc-oxidized magnesium implants: a microCT study in rats. Acta Biomater 9:5411-5420. https://doi. org/10.1016/J.ACTBIO.2012.09.017

Geng F, Tan L, Zhang B et al (2009) Study on beta-TCP coated porous $\mathrm{Mg}$ as a Bone tissue engineering scaffold material. J Mater Sci Technol 25:123-129

Gibson LJ (1985) The mechanical behaviour of cancellous bone. J Biomech 18:317-328. https://doi.org/10.1016/0021-9290(85)90287-8

Gong T, Xie J, Liao J et al (2015) Nanomaterials and bone regeneration. Bone Res 3:15029. https://doi.org/10.1038/boneres.2015.29

Gu X, Zheng Y, Cheng Y et al (2009) In vitro corrosion and biocompatibility of binary magnesium alloys. Biomaterials 30:484-498. https://doi.org/10.1016/j.biomaterials.2008.10.021

Gu XN, Zhou WR, Zheng YF et al (2010) Degradation and cytotoxicity of lotus-type porous pure magnesium as potential tissue engineering scaffold material. Mater Lett 64:1871-1874. https://doi. org/10.1016/j.matlet.2010.06.015

Hedberg EL, Shih CK, Lemoine JJ et al (2005) In vitro degradation of porous poly(propylene fumarate)/poly(dl-lactic-co-glycolic acid) composite scaffolds. Biomaterials 26:3215-3225. https:// doi.org/10.1016/J.BIOMATERIALS.2004.09.012
Helgason B, Perilli E, Schileo E et al (2008) Mathematical relationships between bone density and mechanical properties: a literature review. Clin Biomech 23:135-146. https://doi.org/10.1016/j.clinb iomech.2007.08.024

Jasmawati N, Fatihhi S, Putra A et al (2017) Mg-based porous metals as cancellous bone analogous material: a review. Proc Inst Mech Eng Part L J Mater Des Appl 231:544-556. https://doi. org/10.1177/1464420715624449

Jiang G, He G (2014) A new approach to the fabrication of porous magnesium with well-controlled 3D pore structure for orthopedic applications. Mater Sci Eng, C 43:317-320. https://doi. org/10.1016/j.msec.2014.07.033

Judex S, Boyd S, Qin Y-X et al (2003) Combining high-resolution micro-computed tomography with material composition to define the quality of bone tissue. Curr Osteoporos Rep 1:11-19. https:// doi.org/10.1007/s11914-003-0003-x

Lacroix D, Planell JA, Prendergast PJ (2009) Computer-aided design and finite-element modelling of biomaterial scaffolds for bone tissue engineering. Philos Trans R Soc A Math Phys Eng Sci 367:1993-2009. https://doi.org/10.1098/rsta.2009.0024

Lewis G (2013) Properties of open-cell porous metals and alloys for orthopaedic applications. J Mater Sci Mater Med 24:2293-2325. https://doi.org/10.1007/s10856-013-4998-y

Liu XS, Bevill G, Keaveny TM et al (2009) Micromechanical analyses of vertebral trabecular bone based on individual trabeculae segmentation of plates and rods. J Biomech 42:249-256. https://doi. org/10.1016/j.jbiomech.2008.10.035

Md Saad AP, Syahrom A (2018) Study of dynamic degradation behaviour of porous magnesium under physiological environment of human cancellous bone. Corros Sci 131:45-56. https://doi. org/10.1016/j.corsci.2017.10.026

Md. Saad AP, Jasmawati N, Harun MN et al (2016) Dynamic degradation of porous magnesium under a simulated environment of human cancellous bone. Corros Sci 112:1-12. https://doi. org/10.1016/j.corsci.2016.08.017

Md Saad AP, Abdul Rahim RA, Harun MN et al (2017) The influence of flow rates on the dynamic degradation behaviour of porous magnesium under a simulated environment of human cancellous bone. Mater Des 122:268-279. https://doi.org/10.1016/j.matde s.2017.03.029

Milan J, Planell JA, Lacroix D (2009) Biomaterials computational modelling of the mechanical environment of osteogenesis within a polylactic acid - calcium phosphate glass scaffold. Biomaterials 30:4219-4226. https://doi.org/10.1016/j.biomaterials.2009.04.026

Mistry AS, Pham QP, Schouten C et al (2010) In vivo bone biocompatibility and degradation of porous fumarate-based polymer/alumoxane nanocomposites for bone tissue engineering. J Biomed Mater Res-Part A 92:451-462. https://doi.org/10.1002/jbm.a.32371

Morgan EF, Keaveny TM (2001) Dependence of yield strain of human trabecular bone on anatomic site. J Biomech 34:569-577. https:// doi.org/10.1016/S0021-9290(01)00011-2

Perilli E, Baleani M, Öhman C et al (2008) Dependence of mechanical compressive strength on local variations in microarchitecture in cancellous bone of proximal human femur. J Biomech 41:438446. https://doi.org/10.1016/j.jbiomech.2007.08.003

Planell JA, Lacroix D, Olivares AL (2009) Biomaterials finite element study of scaffold architecture design and culture conditions for tissue engineering. 30:6142-6149. https://doi.org/10.1016/j.bioma terials.2009.07.041

Renders GAP, Mulder L, van Ruijven LJ, van Eijden TMGJ (2007) Porosity of human mandibular condylar bone. J Anat 210:239248. https://doi.org/10.1111/j.1469-7580.2007.00693.x

Shi X, Wang X, Niebur GL (2009) Effects of loading orientation on the morphology of the predicted yielded regions in trabecular bone. Ann Biomed Eng 37:354-362. https://doi.org/10.1007/s1043 9-008-9619-4 
Shimko DA, Shimko VF, Sander EA et al (2005) Effect of porosity on the fluid flow characteristics and mechanical properties of tantalum scaffolds. J Biomed Mater Res Part B Appl Biomater 73B:315-324. https://doi.org/10.1002/JBM.B.30229

Snyder BD, Piazza S, Edwards WT, Hayes WC (1993) Role of trabecular morphology in the etiology of age-related vertebral fractures. Calcif Tissue Int 53:14-22. https://doi.org/10.1007/BF01673396

Staiger MP, Pietak AM, Huadmai J, Dias G (2006) Magnesium and its alloys as orthopedic biomaterials: a review. Biomaterials 27:1728-1734. https://doi.org/10.1016/j.biomaterials.2005.10.003

Sulong MA, Belova IV, Boccaccini AR et al (2016) A model of the mechanical degradation of foam replicated scaffolds. J Mater Sci 51:3824-3835. https://doi.org/10.1007/s10853-015-9701-x

Syahrom A, Abdul Kadir MR, Abdullah J, Öchsner A (2011) Mechanical and microarchitectural analyses of cancellous bone through experiment and computer simulation. Med Biol Eng Comput 49:1393-1403. https://doi.org/10.1007/s11517-011-0833-0

Syahrom A, Abdul Kadir MR, Abdullah J, Öchsner A (2013) Permeability studies of artificial and natural cancellous bone structures. Med Eng Phys 35:792-799. https://doi.org/10.1016/j.meden gphy.2012.08.011

Tamburaci S, Tihminlioglu F (2018) Biosilica incorporated 3D porous scaffolds for bone tissue engineering applications. Mater Sci Eng, C 91:274-291. https://doi.org/10.1016/j.msec.2018.05.040

Uth N, Mueller J, Smucker B, Yousefi A-M (2017) Validation of scaffold design optimization in bone tissue engineering: finite element modeling versus designed experiments. Biofabrication 9:015023. https://doi.org/10.1088/1758-5090/9/1/015023

Vesenjak M, Sulong MA, Krstulović-Opara L et al (2016) Dynamic compression of aluminium foam derived from infiltration casting of salt dough. Mech Mater 93:96-108. https://doi.org/10.1016/j. mechmat.2015.10.012

Vormann J (2003) Magnesium: nutrition and metabolism. Mol Aspects Med 24:27-37. https://doi.org/10.1016/S0098-2997(02)00089-4

Williams AFO, McCullough MBA (2015) Micro-computed tomography to finite element analysis of in vivo biodegradable magnesium-alloy screw and surrounding bone in rabbit femurs. In: Volume 14: emerging technologies; safety engineering and risk analysis; materials: genetics to structures. ASME, pp. V014T11A035; 9 pages. https://doi.org/10.1115/IMECE 2015-52790

Witte F, Ulrich H, Palm C, Willbold E (2007a) Biodegradable magnesium scaffolds: part II: peri-implant bone remodeling. J Biomed Mater Res A 81:757-765. https://doi.org/10.1002/jbm.a.31293

Witte F, Ulrich H, Rudert M, Willbold E (2007b) Biodegradable magnesium scaffolds: part 1: appropriate inflammatory response. J Biomed Mater Res A 81:748-756. https://doi.org/10.1002/ jbm.a. 31170

Witte F, Hort N, Vogt C et al (2008) Degradable biomaterials based on magnesium corrosion. Curr Opin Solid State Mater Sci 12:63-72. https://doi.org/10.1016/j.cossms.2009.04.001

Yazdimamaghani M, Razavi M, Vashaee D, Tayebi L (2015) Surface modification of biodegradable porous $\mathrm{Mg}$ bone scaffold using polycaprolactone/bioactive glass composite. Mater Sci Eng, C 49:436-444. https://doi.org/10.1016/j.msec.2015.01.041

Yu Y, Lu H, Sun J (2018) Long-term in vivo evolution of high-purity $\mathrm{Mg}$ screw degradation-Local and systemic effects of $\mathrm{Mg}$ degradation products. Acta Biomater 71:215-224. https://doi. org/10.1016/J.ACTBIO.2018.02.023

Zhang X, Li X-W, Li J-G, Sun X-D (2014) Preparation and mechanical property of a novel $3 \mathrm{D}$ porous magnesium scaffold for bone tissue engineering. Mater Sci Eng C Mater Biol Appl 42:362-367. https ://doi.org/10.1016/j.msec.2014.05.044

Zheng YF, Gu XN, Witte F (2014) Biodegradable metals. Mater Sci Eng R Reports 77:1-34. https://doi.org/10.1016/j. mser.2014.01.001

Publisher's Note Springer Nature remains neutral with regard to jurisdictional claims in published maps and institutional affiliations. 